\title{
15 Level Single Phase Multilevel Inverter Topology with Equal Area Criteria PWM Technique
}

\author{
B. T. Venu Gopal ${ }^{1}$, N.Yashwanth Kumar ${ }^{2}$, E. G. Shivakumar ${ }^{3}$ \\ Department of Electrical Engineering \\ UVCE, Bangalore University \\ Bengaluru, India \\ Email : btvgopal@gmail.com¹, yash7wip@gmail.com², shivaettigi@gmail.com
}

\begin{abstract}
- 90 percent of the motors used in industries are induction motors due to its simple design and high robustness. Total Harmonic Distortion of output voltage waveform keeps decreasing as the number of voltage levels increases. The main consideration while selecting a multilevel inverter is its quality of the output voltage waveform which is assessed in terms of the amount of harmonics content present in it. So, Total Harmonic Distortion (THD) value in the output voltage waveform is one of the important criteria in the multilevel inverter (MLI). The 15 level hybrid multilevel inverter circuit was simulated in Matlab/Simulink environment and the results were experimentally analysed for a resistive load. $\mathrm{C}$ code was developed to generate PWM pulses. Arduino microcontroller is used to feed the PWM pulses to the switches in the inverter circuit. From the overall analysis, it is proved that the Equal Area Criteria (EAC) method is superior to the other PWM methods.
\end{abstract}

\section{Keywords-Equal Area Criteria PWM method, Arduino Microcontroller, THD, 15 level MLI}

\section{INTRODUCTION}

In the power industry, two-level and three-level inverters are used for low and medium power applications respectively [1]. The two-level voltage source inverters are the inverters which produce an output voltage with levels either 0 or \pm V_dc. To get almost sine waveform at the output with less THD, they need high switching frequency with various Pulse Width Modulation (PWM) methods. However, when it comes to high voltage and high power application, 2 level inverters have some drawbacks during operation at high frequency mainly due to switching losses [2].

Multi-level inverters have occupied considerable attention in the last few years due to their various advantages [3]. The main concept of multi-level inverters is the utilization of several power semiconductor switches to do the DC-AC transformation in little voltage steps. Small voltage steps support to get the low THD, less switching losses and higher efficiency. Also, it performs the reduction of $\partial v / \partial t$ stresses. Such multilevel inverter methods allow a considerable reduction in the size of the output filter, reducing the number of switches and an increase in efficiency [4]. Capacitors, batteries and solar panels can be used as dc voltage sources [5].

Advantages of MLI are as follows:

It helps us to get almost sine waveform at the output with less THD, low $\partial \mathrm{v} / \partial \mathrm{t}$ stresses; hence electromagnetic compatibility issues can be reduced.

Common-mode voltage: Multi-level inverters have smaller Common Mode voltage; so, the stress in the motor bearings fed by a multi-level motor drive will be decreased. Moreover, Common Mode voltage could be wiped off by using modern modulation techniques that are proposed.

Switching frequency: Multi-level inverters can work with both high switching frequency and fundamental switching frequency PWM. The main thing to be noted is that lesser switching frequency means lesser switching losses and more efficiency.

Classification of Switching Techniques For Multilevel Inverters

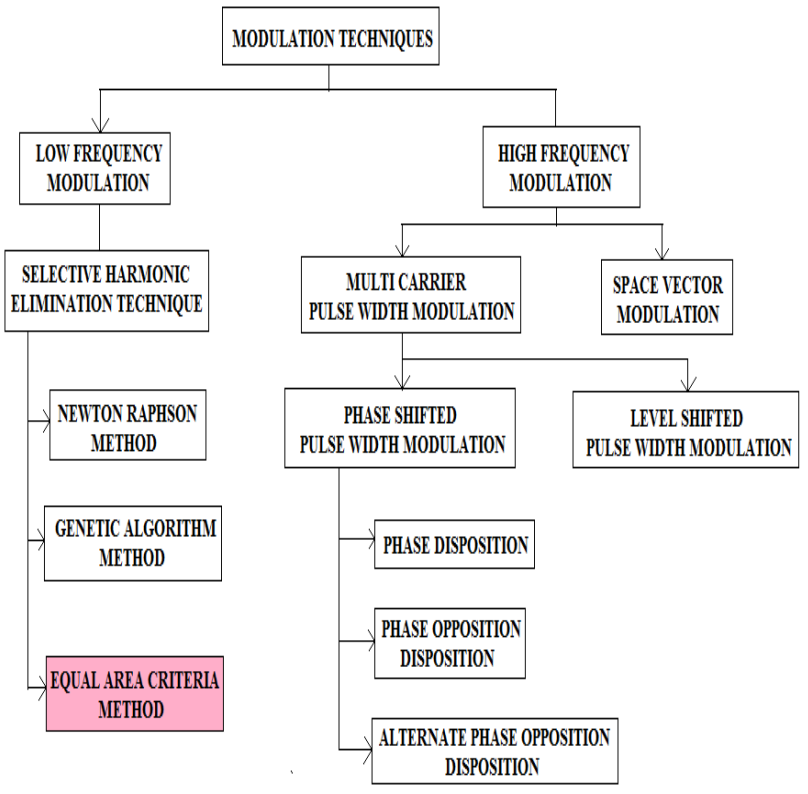

Fig. 1. Different switching techniques

One of the popular switching techniques is to generate gating pulses for driving MLI switches is Pulse Width Modulation (PWM) technique. By comparing fundamental sinusoidal waveform to the carrier wave (triangular)[6].

Difficulties found in other PWM techniques:

- For N-levels we require N-1 carrier waves. 
- The switching power losses will be more because of carrier wave signal frequency which is in the order of few hundreds of fundamental wave frequency. To dissipate this generated heat we need big heat sinks.

- The control circuit complexity will increase. Thus the efficiency of inverter drastically reduces.

- Very high difficulty in the computation of mathematical equations and also difficulty in programming [7].

\section{PROPOSED MLI TOPOLOGY}

The topology is consists of 7 switches and 3 Asymmetrical DC voltage sources and is shown in Figure 3.1. The H-bridge is mainly used for polarity change as well as to control the minimum step voltage i.e. Vdc.

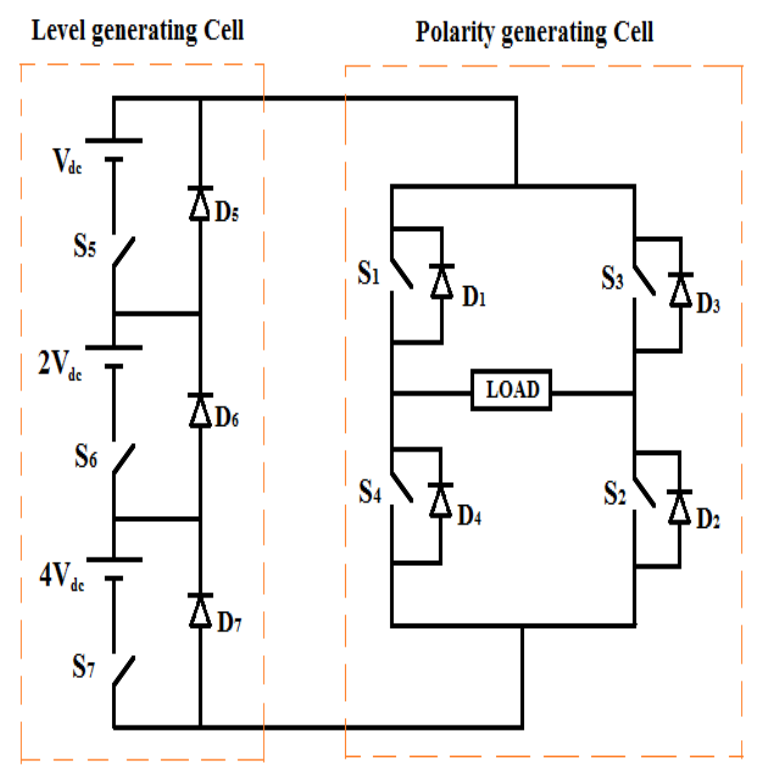

Fig 2. Circuit diagram of the proposed 15 levels MLI Topology

The circuit diagram of the suggested 15 levels of hybrid multilevel inverter is shown in fig. 2. This inverter consists of two conversion cells, 1 is for level generation and another is for polarity generation. The level generating cell contains three switches \& DC voltage sources which are responsible for the generation of 15 levels in output voltage. The polarity generating cell consists of an H-bridge which is responsible for the generation of +ve and -ve polarities in output voltage. The input DC voltage sources are in the ratio 1: 2: 4. Asymmetric voltage sources are used to obtain sine waveform [8]. By incorporating proper PWM method, harmonics in output voltage is reduced thereby an output voltage with minimum THD is achieved.

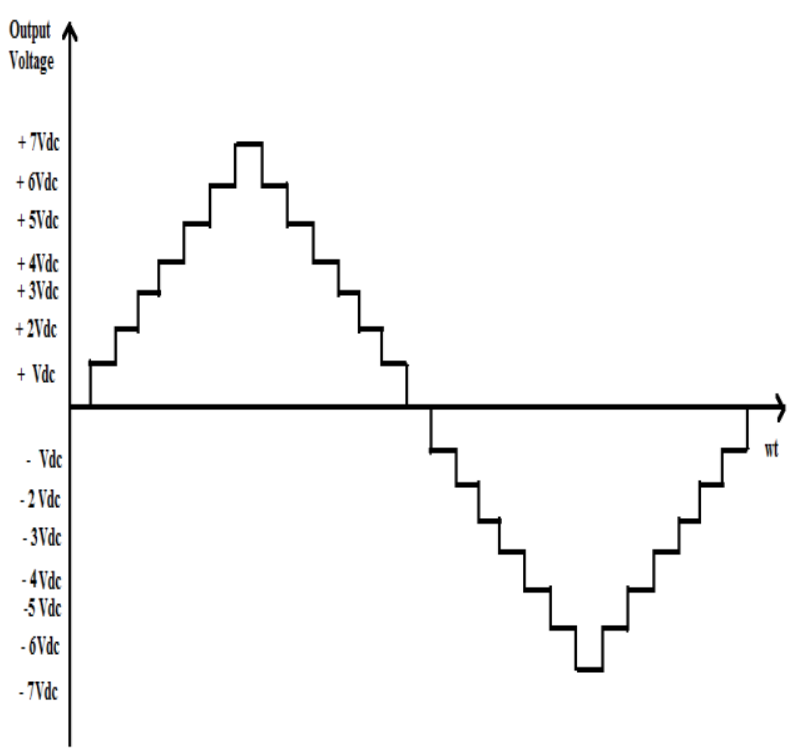

Fig 3. Fifteen Level MLI Output voltage waveform

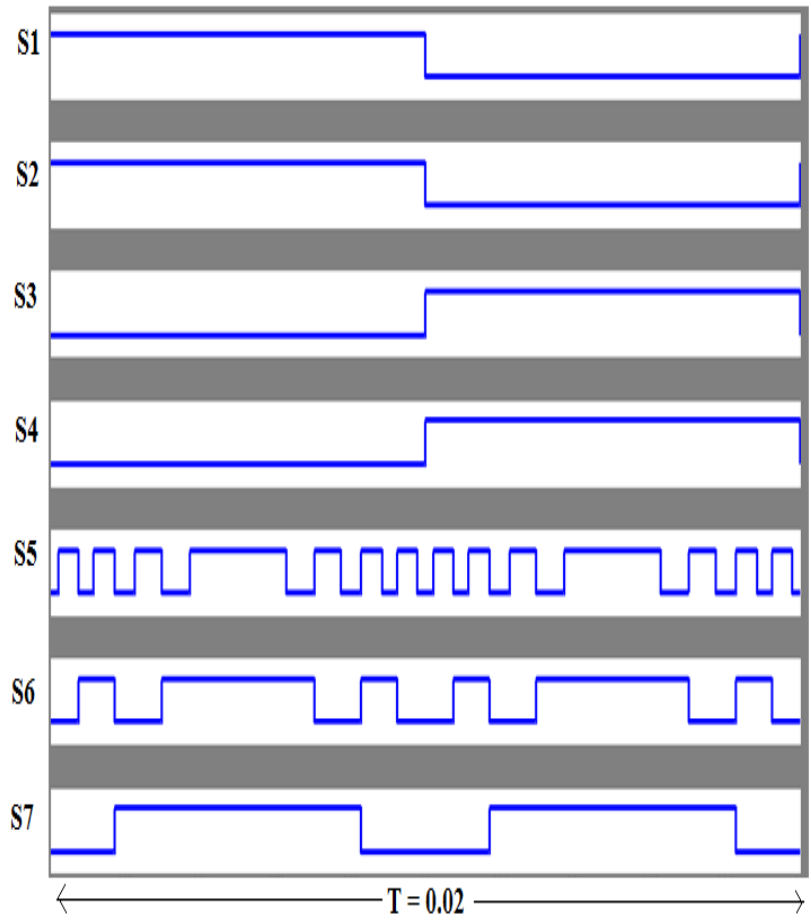

Fig.4. Switching pulses for the proposed Topology 
A. Equal Area Criteria Switching Technique

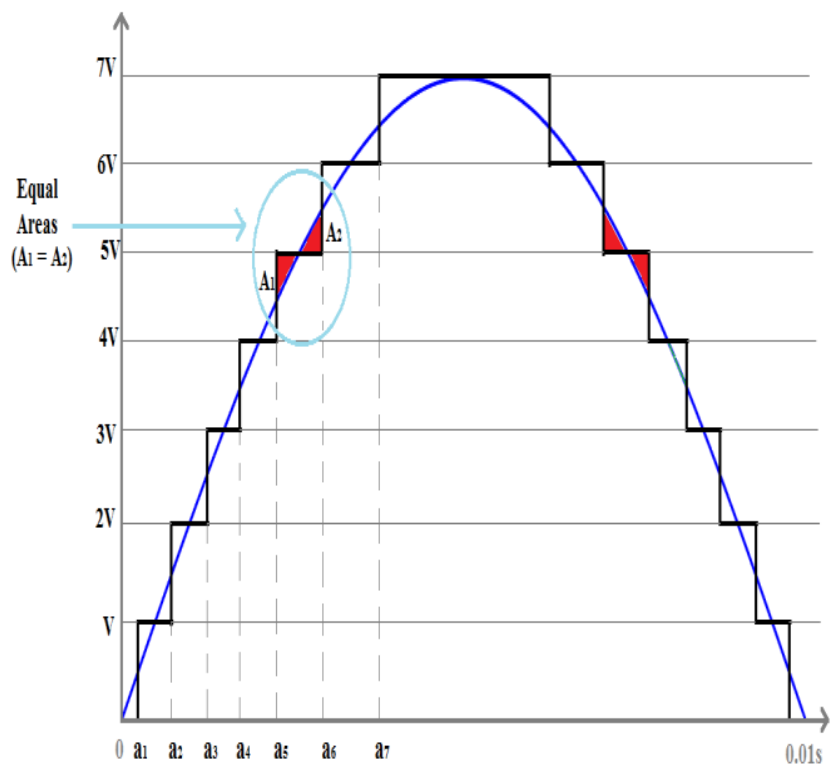

Fig.5. EAC PWM Technique

Accurate switching angels can be determined by using the EAC method. The fundamental form of the sine wave is divided both vertically and horizontally in terms of step voltage and time (mili seconds).

In the above diagram, to achieve low THD areas A1 and A2 must be equal. We have taken fundamental frequency as $50 \mathrm{~Hz}$. Minimum voltage suggested in level generation circuit is called as step voltage. Switching angels for $\mathrm{N}$ level multilevel inverter is given by $\mathrm{a} 1, \mathrm{a} 2, \mathrm{a} 3, \ldots$ an.

$0<\mathrm{a} 1<\mathrm{a} 2<\mathrm{a} 3<\mathrm{a} 4<\mathrm{a} 5<\mathrm{a} 6<\mathrm{a} 7--$ an $<90^{\circ}$

Total no. of switching angles for $\mathrm{N}$-levels $=[$ (Number of levels-1)/2]

Angle To Time Conversion:

We know that $\theta=\omega t$

where ' $\omega$ ' is the angular frequency in $\mathrm{rad} / \mathrm{sec}$, ' $\mathrm{t}$ ' is the time in seconds.

$$
t=\frac{\theta}{\omega} \quad \text { and } \quad \omega=2 \pi f
$$

To calculate the $n^{\text {th }}$ switching time,

$$
t_{n}=\frac{a_{n}}{2 * 180 * 50}
$$

In this way the switching angles are converted into time values

The switching angles are obtained for,

\section{5 level MLI}

$a_{1}=2.57^{0}, a_{2}=10.92^{0}, a_{3}=19.28^{0}, a_{4}=28.28^{0}, a_{5}=37.928^{0}$, $\mathrm{a}_{6}=48.857^{0}, \mathrm{a}_{7}=63^{0}$

Inverter circuit switches are turned $\mathrm{ON}$ at above switching angels.

\section{SIMULATION OF 15 LEVEL MLI INVERTER WITH EAC PWM METHOD}

Fig 6 shows the simulation of 15 level MLI using EAC PWM method. The circuit consists of seven switches and three Asymmetrical DC voltage sources of ratio 1:2:4.

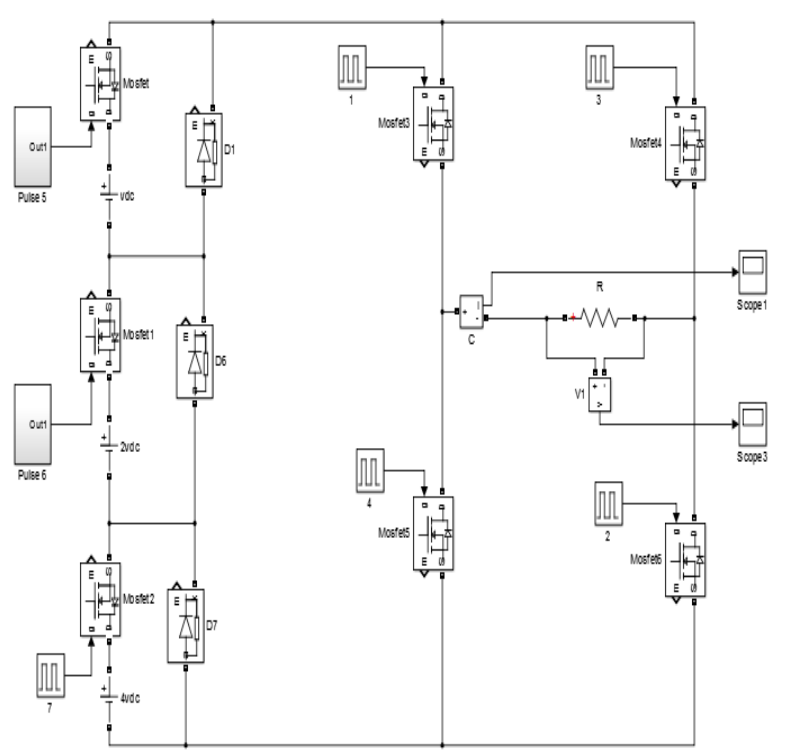

Fig. 6. Simulation circuit of 15 level MLI with EAC technique

A novel method with less number of power switches are used and is simulated for input DC supply of $\mathrm{Vdc}=48 \mathrm{~V}$, $2 \mathrm{Vdc}=96 \mathrm{~V}, 4 \mathrm{Vdc}=192 \mathrm{~V}$, with a Resistive load of $150 \Omega$. The switching angles are obtained using EAC technique and THD of the output voltage is $5.46 \%$. Output voltage waveform and the corresponding FFT spectrum is given below in figures 7 and 8 respectively.

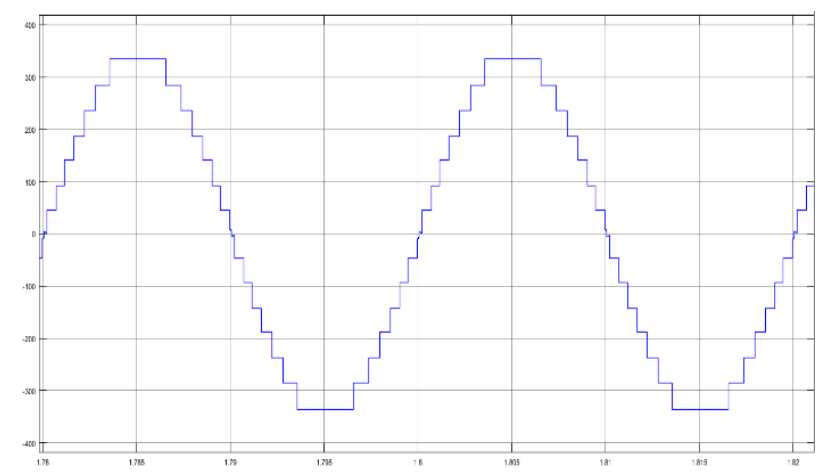

Fig. 7.Output Voltage waveform of 15- Level MLI using EAC technique 


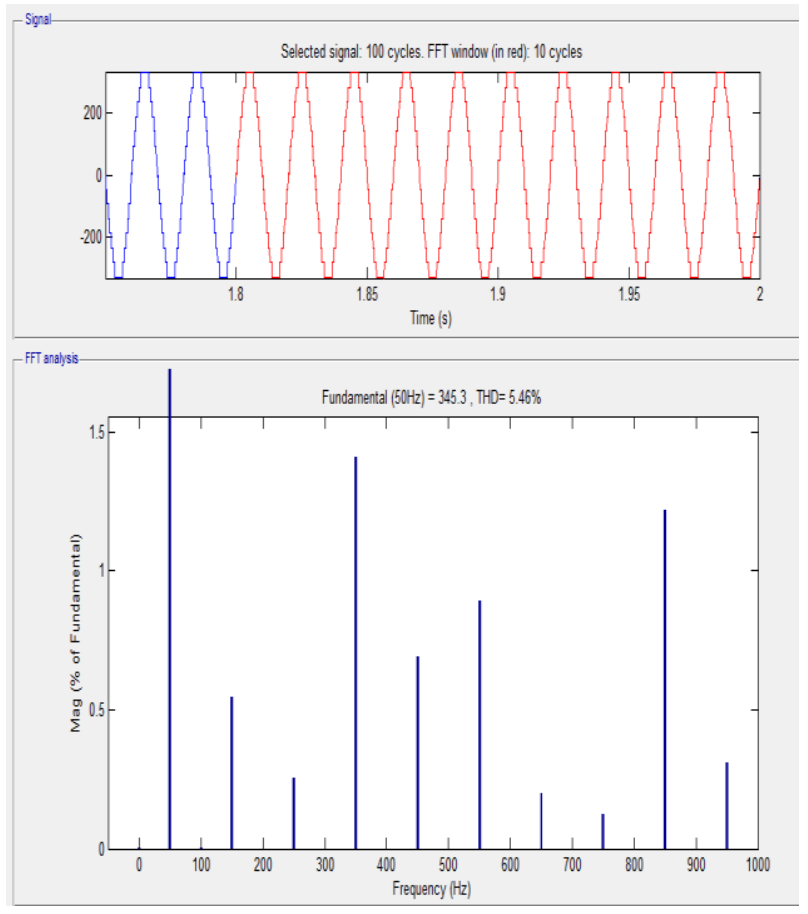

Fig. 8. FFT Spectrum of 15 level output voltage waveform

\section{A. Comparison Of Different Pulse Width Modulation} Techniques with Respect to THD

Fig 9 shows the reduction in the THD for the suggested 15 levels Multi-Level Inverter without using any PWM techniques, with Multi-Carrier PWM technique and Equal Area Criteria Switching technique.

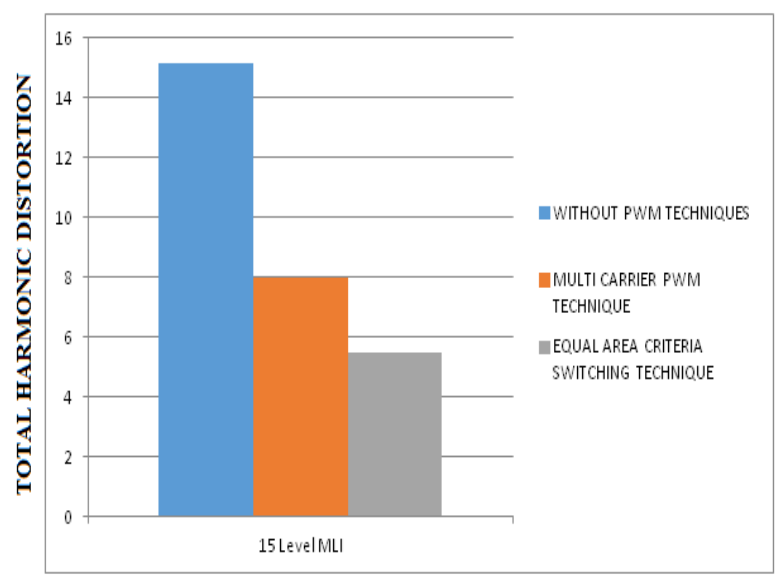

Fig. 9. Comparison of THD for 15 levels MLI with different PWM techniques

It is evident from the Fig 9 that the THD obtained for the proposed 15 levels MLI using Equal Area Criteria method is much lesser when compared to other switching techniques.

\section{HARDWARE IMPLEMENTATION}

The block diagram of the overall system consists of a single-phase fifteen level multilevel inverter which is fed by a DC source input of $42 \mathrm{~V}$. Selected DC voltage sources are $6 \mathrm{~V}, 12 \mathrm{~V}$ and $24 \mathrm{~V}$. ARDUINO microcontroller is programmed to generate the desired PWM pulses which are fed to the power switches in inverter circuit through a driver circuit. A resistive load of 3 kilo ohms is used.

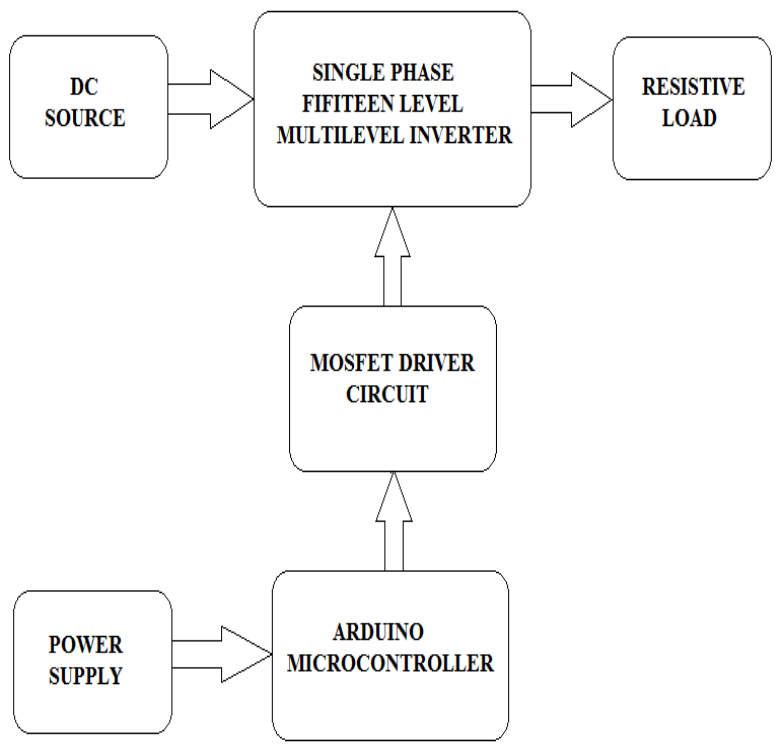

Fig. 10. Block diagram of the hardware setup

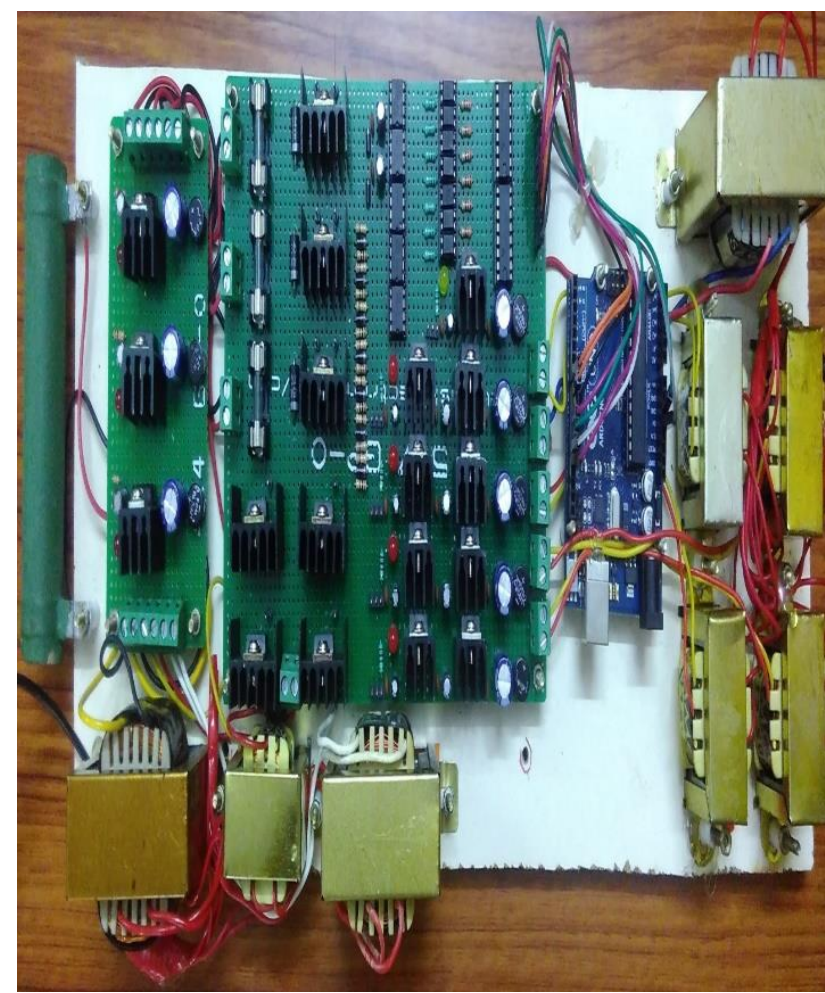

Fig. 11. The hardware setup of 15-Level Inverter 


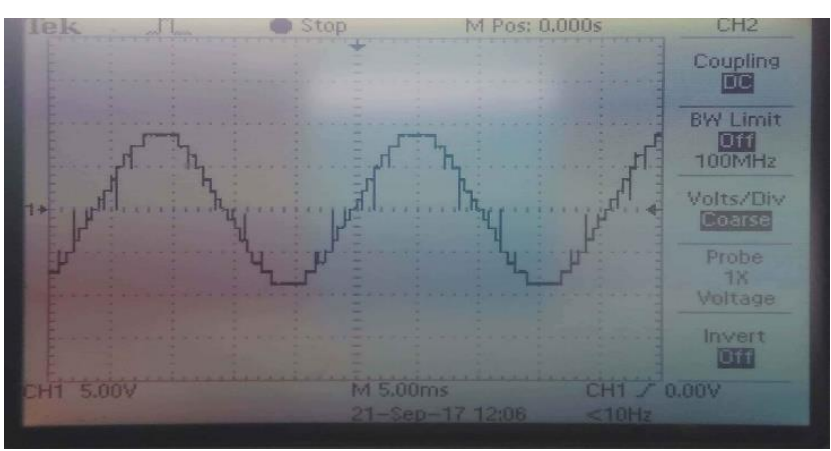

Fig. 12. CRO Output Voltage of 15-Level MLI

\section{CONCLUSION AND FUTURE SCOPE}

15 level MLI with Equal Area Criteria method has been presented in this work, the percentage of lower order harmonics is reduced using EAC switching angle calculation technique. The Total Harmonic Distortion in the output voltage of 15 - level multilevel inverter is reduced to $5.46 \%$.

The input DC voltage sources can be replaced with the output of solar panels and the DC voltage is boosted up using boost converters to the required value. The output of this inverter can be used for residential buildings and consumer applications like household appliances. Using the Internet of Things (IoT) concept wireless control if the induction motor can be implemented. Same control technique may be utilized to drive constant speed 3 phase induction motor. By using Silicon Carbide based MOSFETs and Litz wires which have high thermal efficiency and high power handling capability, switching losses can be reduced. Nowadays, Switched Reluctance Motors is attracting huge attention due to its advantages over induction motor. It is a very fresh concept. Similar control technique can be implemented to control the Switched Reluctance Motors. Instead of Code Compressor Studio, we can use Texas Instruments based Energia software, it is very simple compared to Code Compressor Studio.

\section{REFERENCES}

[1]. Ceglia, Gerardo, Victor Guzman, Carlos Sanchez, Fernando Ibanez, Julio Walter, and María I. Giménez. "A new simplified multilevel inverter topology for DC-AC conversion." IEEE transactions on power electronics 21, no. 5 (2006): 1311-1319.

[2]. Rodriguez, Jose, Jih-Sheng Lai, and Fang Zheng Peng. "Multilevel inverters: a survey of topologies, controls, and applications." IEEE Transactions on industrial electronics 49, no. 4 (2002): 724-738.

[3Babaei, Ebrahim, Somayeh Alilu, and Sara Laali. "A new general topology for cascaded multilevel inverters with reduced number of components based on developed H-bridge." IEEE Transactions on Industrial Electronics 61, no. 8 (2013): 39323939.
[4]. Bhaskar, K. B., T. S. Sivakumaran, and M. Devi. "Analysis of asymmetrical cascaded multi-cell multilevel inverter employing multicarrier level shifting pwm technique on different loads." IDNJST 31 (2016).

[5] Leedy, A. W., and R. M. Nelms. "Harmonic analysis of a threelevel sinusoidal pwm inverter using the method of pulse pairs." In 2006 IEEE International Symposium on Industrial Electronics, vol. 2, pp. 1188-1193. IEEE, 2006.

[6]. Rashid, Muhammad H. "Power Electronic Circuits, Devices, and Applications." In University of West Florida. Pearson Prentice Hall, 2004.

[7]. Shivakumar E.G. , Ramesh H.R, and Palemkota Mahesh, "Comparison of Hybrid Multi Level Inverter Topologies using Equal Area Criteria", International Journal of Advanced Research in Electrical, Electronics and Instrumentation Engineering, Vol. 5(6),2016

[8]. Remyasree.R and Dona Sebastian, "Fifteen Level Hybrid Cascaded Inverter", International Journal of Advanced Research in Electrical, Electronics and Instrumentation Engineering Vol. 4(9),2015. 